\title{
Studies on Ion Association and Solvent Interaction- Conductance of Glycine in Aqueous Solutions of Hydrotropic Agents at Different Temperatures
}

\author{
SMRUTI PATTNAIK and UPENDRA NATH DASH* \\ Department of Chemistry, Institute of Technical Education and Research (ITER), \\ Siksha 'O' Anusandhan Deemed to be University, Bhubaneswar-751030, Odisha, India \\ dr.upendranath.dash@gmail.com
}

Received 1 March 2013 / Accepted 19 March 2013

\begin{abstract}
The conductance values of glycine have been measured in the concentration range of 0.006 to $0.08 \mathrm{~mol} \mathrm{dm}^{-3}$ in aqueous and aqueous solutions of hydrotropic agents (viz., sodium bromide, sodium benzoate and nicotinamide) of $0.1,0.2$ and $0.3 \mathrm{wt} \%$ at different temperatures ranging from $298.15 \mathrm{~K}$ to $313.15 \mathrm{~K}$ at an interval of $5 \mathrm{~K}$. The conductance data have been computed by Shedlovsky equation to obtain $\Lambda_{\mathrm{m}}^{0}$ and $\mathrm{K}_{\mathrm{A}}$. Based upon the composition dependence of Walden Product, the influence of the hydrotropic agents on the solvation of ions has been discussed. The values of association constant $\mathrm{K}_{\mathrm{A}}$ are used to obtain the standard thermodynamic quantities, such as $\Delta \mathrm{G}^{0}, \Delta \mathrm{H}^{0}$ and $\Delta \mathrm{S}^{0}$, for the association process in the solution. It has been observed that the electronic contribution is totally negligible toward the standard transfer thermodynamic quantities.
\end{abstract}

Keywords: Hydrotropic agents, Glycine, Molar conductance, Association constant

\section{Introduction}

Solubility and permeability are the two biopharmaceutical parameters responsible for effective bioavailability and good in vitro and in vivo correlation. Enhancement of solubility and dissolution rate and oral bioavailability of glycine (Amino acid) are still the challenging aspects for the pharmaceutical technologists. Hydrotropic solubilisation action of glycine is considered as one of the important methods of solubilisation. Conductometric studies of glycine at definite and infinite dilution in a solvent system provide valuable information regarding the ion-ion and ion-solvent interactions. By examining the limiting molar conductivity $\left(\Lambda_{\mathrm{m}}^{0}\right)$, association constant $\left(\mathrm{K}_{\mathrm{A}}\right)$ and Walden Products $\left(\Lambda_{\mathrm{m}}^{0} \eta_{0}\right)$ of ionic solutions as function of size, nature, temperature and composition of the solvent, it is possible to examine the parameters on solutesolvent interaction with the hope of obtaining a better understanding of interactions in solution. The present study aimed at highlighting the solute (glycine)- solvent (water) interactions and related modifications in the presence of hydrotropic agents, such as sodium bromide ( $\mathrm{SBr}$ ), sodium benzoate $(\mathrm{SB})$ and nicotinamide $(\mathrm{N})$ with three different compositions of $0.1,0.2$ and $0.3 \mathrm{wt} \%$ at different temperatures ranging from $298.15 \mathrm{~K}$ to $313.15 \mathrm{~K}$. 


\section{Experimental}

All chemicals used were of GR or BDH, AnalaR grades. Conductivity water (Specific conductance $\approx 10^{-6} \mathrm{Scm}^{-1}$ ) was used for preparing aqueous solutions of hydrotropic agents $(0.1,0.2$ and $0.3 \%(\mathrm{~W} / \mathrm{W})$. The hydrotropic agents content in the mixture was accurate to within $\pm 0.01 \%$. The solutions of glycine were prepared in different compositions of the hydrotropic agents on the molal basis which were than converted into molar basis by usual method $^{1}$ by using the density value of the glycine solution. The concentration of the solution ranges from $1 \times 10^{-3}$ to $6 \times 10^{-2}$ molar. The conductance values of the solutions were measured by means of a conductivity meter (Elico make) at a cell constant of $1 \mathrm{~S} \mathrm{~cm}^{-1}$ at different temperatures. The viscosity coefficients of the glycine solutions in different compositions of hydrotropic agents are determined at temperatures ranging from $298.15 \mathrm{~K}$ to $313.15 \mathrm{~K}$ by means of an Ostwald Viscometer as described elsewhere ${ }^{2}$.

\section{Results and Discussion}

The experimental values of the conductance measurements for glycine in aqueous solutions of $\mathrm{SB}, \mathrm{SBr}$ and $\mathrm{N}$ in three wt\% (0.1, 0.2 and 0.3$)$ after solvent correction were analysed using Shedlovsky equation ${ }^{3}$. The limiting molar conductivity values, $\Lambda_{\mathrm{m}}^{0}$ are obtained by using the value of ion-size parameter $\mathrm{a}_{0}=\mathrm{q}$ as $\mathrm{a}_{0}=0, \mathrm{q}$, and $2 \mathrm{q}$ are very close to each other ${ }^{4}$. The calculated values of $\mathrm{K}_{\mathrm{A}}$, the ion-association constant and $\Lambda_{\mathrm{m}}^{0}$ of glycine value in aqueous solutions of $\mathrm{SB}, \mathrm{SBr}$ and $\mathrm{N}$ are given in Table 1 at experimental temperatures. Table 1 also contains the values of Walden product, $\Lambda_{\mathrm{m}}^{0} \eta_{0}$ for glycine.

Table 1. Values of $\Lambda_{\mathrm{m}}^{0}\left(\mathrm{Scm}^{2} \mathrm{~mol}^{-1}\right), \mathrm{K}_{\mathrm{A}}\left(\mathrm{dm}^{3} \mathrm{~mol}^{-1}\right)$ and $\Lambda_{\mathrm{m}}^{0} \eta_{0}$ of glycine in $\mathrm{SB}, \mathrm{SBr}$ and $\mathrm{N}$ in water at different temperatures

\begin{tabular}{|c|c|c|c|c|c|}
\hline Glycine & $\mathrm{Wt} \%$ & Temperature, K & $\Lambda_{\mathrm{m}}^{0}$ & $\mathrm{~K}_{\mathrm{A}}$ & $\Lambda_{\mathrm{m}}^{0} \eta_{0}$ \\
\hline \multirow[t]{16}{*}{ SB } & 0.0 & 298.15 & $132.6 \pm 6.3$ & 24.12 & 142.6 \\
\hline & & 303.15 & $148.5 \pm 6.6$ & -6.14 & 138.4 \\
\hline & & 308.15 & $152.3 \pm 6.9$ & -2.12 & 122.2 \\
\hline & & 313.15 & $161.6 \pm 7.0$ & -1.16 & 110.4 \\
\hline & 0.1 & 298.15 & $120.5 \pm 6.3$ & 22.11 & 108.02 \\
\hline & & 303.15 & $137.5 \pm 6.6$ & -3.07 & 104.04 \\
\hline & & 308.15 & $149.7 \pm 6.6$ & -5.39 & 102.06 \\
\hline & & 313.15 & $161.4 \pm 6.9$ & -2.19 & 93.77 \\
\hline & 0.2 & 298.15 & $112.7 \pm 5.7$ & 19.12 & 90.03 \\
\hline & & 303.15 & $127.5 \pm 5.5$ & -5.09 & 91.02 \\
\hline & & 308.15 & $133.7 \pm 6.0$ & -7.19 & 87.03 \\
\hline & & 313.15 & $149.3 \pm 6.1$ & -3.3 & 84.63 \\
\hline & 03 & 298.15 & $100.5 \pm 5.1$ & 17.22 & 89.53 \\
\hline & & 303.15 & $92.3 \pm 5.3$ & -3.09 & 86.12 \\
\hline & & 308.15 & $86.4 \pm 5.1$ & -6.13 & 87.22 \\
\hline & & 313.15 & $81.5 \pm 5.3$ & -2.12 & 82.12 \\
\hline \multirow[t]{5}{*}{$\mathrm{SBr}$} & 0.0 & 298.15 & $172.0 \pm 6.3$ & -16.03 & 172.8 \\
\hline & & 303.15 & $178.6 \pm 6.6$ & -4.22 & 179.6 \\
\hline & & 308.15 & $182.4 \pm 6.9$ & 14.62 & 183.4 \\
\hline & & 313.15 & $190.6 \pm 7.0$ & 3.29 & 192.6 \\
\hline & 0.1 & 298.15 & $161.3 \pm 6.3$ & -19.02 & 149.86 \\
\hline
\end{tabular}




\begin{tabular}{|c|c|c|c|c|c|}
\hline & & 303.15 & $178.5 \pm 6.6$ & -3.68 & 164.32 \\
\hline & & 308.15 & $199.3 \pm 6.3$ & 12.62 & 172.61 \\
\hline & & 313.15 & $222.6 \pm 6.6$ & 2.69 & 169.32 \\
\hline & 0.2 & 298.15 & $151.8 \pm 5.7$ & -21.06 & 136.35 \\
\hline & & 303.15 & $163.6 \pm 5.5$ & -1.29 & 141.26 \\
\hline & & 308.15 & $168.5 \pm 6.0$ & -3.64 & 139.32 \\
\hline & & 313.15 & $176.4 \pm 6.1$ & 11.63 & 143.26 \\
\hline & 0.3 & 298.15 & $143.6 \pm 5.1$ & -23.12 & 127.25 \\
\hline & & 303.15 & $149.5 \pm 5.3$ & -2.66 & 131.33 \\
\hline & & 308.15 & $156.3 \pm 5.1$ & -1.28 & 129.22 \\
\hline & & 313.15 & $161.2 \pm 5.3$ & 12.61 & 132.31 \\
\hline \multirow[t]{16}{*}{$\mathrm{N}$} & 0.0 & 298.15 & $176.2 \pm 6.3$ & -23.11 & 140.6 \\
\hline & & 303.15 & $171.4 \pm 6.6$ & -5.12 & 124.2 \\
\hline & & 308.15 & $162.6 \pm 6.9$ & -19.23 & 121.4 \\
\hline & & 313.15 & $158.8 \pm 7.0$ & 6.14 & 98.2 \\
\hline & 0.1 & 298.15 & $163.4 \pm 6.3$ & -22.77 & 96.4 \\
\hline & & 303.15 & $141.3 \pm 6.6$ & -26.05 & 88.6 \\
\hline & & 308.15 & $137.2 \pm 6.3$ & -26.60 & 84.2 \\
\hline & & 313.15 & $131.4 \pm 6.6$ & -27.02 & 80.2 \\
\hline & 0.2 & 298.15 & $157.3 \pm 5.7$ & -23.12 & 78.4 \\
\hline & & 303.15 & $137.2 \pm 5.5$ & -27.34 & 74.6 \\
\hline & & 308.15 & $129.3 \pm 6.0$ & -27.72 & 72.4 \\
\hline & & 313.15 & $121.6 \pm 6.1$ & -28.13 & 66.2 \\
\hline & 03 & 298.15 & $143.6 \pm 5.1$ & -25.06 & 64.6 \\
\hline & & 303.15 & $129.2 \pm 5.3$ & -29.31 & 62.4 \\
\hline & & 308.15 & $118.3 \pm 5.1$ & -31.12 & 58.4 \\
\hline & & 313.15 & $107.3 \pm 5.3$ & -33.06 & 56.2 \\
\hline
\end{tabular}

As observed, the values of $\Lambda_{\mathrm{m}}^{0}$ of glycine in aqueous solutions of hydrotropic agents are very low. This is due to the fact that the hydrodynamic radii of the ions (generated from hydrotropic agents) increase which causes a decrease in their mobility.

It is evident from Table 1 that the values of $\Lambda^{0}{ }_{\mathrm{m}}$ of glycine increase with increase in temperature in aqueous solutions of sodium benzoate (SB) and sodium bromide ( $\mathrm{SBr}$ ), but decrease in aqueous solutions of nicotinamide $(\mathrm{N})$. The increased $\Lambda_{\mathrm{m}}^{0}$ values with increase in temperature indicate less solvation or higher mobility of ions which can be attributed to the fact that the increased thermal energy results in greater bond breaking and variation in vibrational, rotational and translational energy of the molecules that lead to higher frequency and higher mobility of ions ${ }^{5}$. But the reverse is the case in the aqueous solutions of nicotinamide where $\Lambda_{\mathrm{m}}^{0}$ value decreases with increase in temperature and that can be attributed to the increased solvation and hydrodynamic radii of the ions thereby decreasing the mobility. As observed, the values of $\Lambda^{0}$ m of glycine in aqueous sodium bromide solutions $(\mathrm{SBr})$ are higher as compared to others in different $\mathrm{wt} \%$. This is reasonable in view of the difference in transport properties of the hydrated bromide which reflects factors affecting its effective size and strength of the coulombic field in the range of hydration shell. The higher $\Lambda_{\mathrm{m}}^{0}$ values in aqueous solutions of sodium bromide $(\mathrm{SBr})$ are consistent with the lower viscosity values and lower solubility 
of glycine in sodium bromide solutions. The association constant, $\mathrm{K}_{\mathrm{A}}$ values in all solutions show an irregular trend with increase in temperature and also with increase in wt $\%$. This may be attributed to the varying degree of exothermic ion-pair association caused due to difference in ionic stability, specific ion-solvent and solvent-solvent interactions.

The variation of the Walden product $\Lambda_{\mathrm{m}}^{0} \eta_{0}$ (Table 1) is somewhat complex. It is found that Walden product is higher in case of aqueous sodium bromide solution and is lower in nicotinamide solution. The higher value of Walden product indicates weak solvation of the ions. It is known that the variation of Walden product reflects the change of solvation. As the weight percentage of hydrotropic agents increases there is a variation trend observed in Walden product values

Since the conductance measurements of an ion depend upon mobility, it is quite reasonable to treat the conductance data similar to the one employed for the rate process ${ }^{6}$ that takes place with the change in temperature, i.e.,

$$
\Lambda_{\mathrm{m}}^{0}=\mathrm{Ae}^{-\mathrm{Es} / \mathrm{RT}}
$$

Where $\mathrm{A}$ is the frequency factor, $\mathrm{R}$ the gas constant and $\mathrm{E}_{\mathrm{s}}$ is the Arrhenius activation energy of the transport process. From the plot of $\log \Lambda_{\mathrm{m}}^{0}$ versus $\mathrm{I} / \mathrm{T}$, the $\mathrm{E}_{\mathrm{s}}$ values have been computed from the slope $\left(-\mathrm{E}_{\mathrm{s}} / 2.303 \mathrm{R}\right)$ and are given in Table 2 . The standard free energy change for the association process is calculated from equation ${ }^{7}$

$$
\Delta \mathrm{G}^{0}=-\mathrm{RT} \ln \mathrm{K}_{\mathrm{A}}
$$

The heat of association, $\Delta \mathrm{H}^{0}$, is calculated from the slope of the plot of $\ln _{\mathrm{A}}$ versus I/T and the entropy change, $\Delta \mathrm{S}^{0}$, from the Gibbs - Helmholtz equation,

$$
\Delta \mathrm{G}^{0}=\Delta \mathrm{H}^{0}-\mathrm{T} \Delta \mathrm{S}^{0}
$$

The value of the standard thermodynamic parameters are given in Table 2 at $25{ }^{\circ} \mathrm{C}$ only. From Table 2, it is evident that the values of activation energy, $\mathrm{E}_{\mathrm{s}}$, are positive. The free energy change $\Delta G^{0}$ values are negative in sodium benzoate and sodium bromide solutions with glycine. This shows that the association process is favoured over the dissociation process. The positive values of $\Delta \mathrm{H}^{0}$ and $\Delta \mathrm{S}^{0}$ in sodium benzoate solution indicates that the association process is endothermic in nature. The negative values of $\Delta \mathrm{H}^{0}$ and $\Delta \mathrm{S}^{0}$ in sodium bromide solution indicate the association process is exothermic. The positive $\Delta S^{0}$ value indicates the ions are hydrated in these systems.

Table 2. Thermodynamic parameters $\Delta \mathrm{G}^{0}\left(\mathrm{~kJ} \mathrm{~mol}^{-1}\right), \Delta \mathrm{H}^{0}\left(\mathrm{~kJ} \mathrm{~mol}^{-1}\right), \Delta \mathrm{S}^{0}\left(\mathrm{~J} \mathrm{~mol}^{-1} \mathrm{~K}^{-1}\right)$ and $\mathrm{E}_{\mathrm{s}}$ $\left(\mathrm{kJ} \mathrm{mol}{ }^{-1}\right)$ at $25^{0} \mathrm{C}$

\begin{tabular}{cccccc}
\hline Glycine & $\mathrm{Wt} \%$ & $\Delta \mathrm{G}^{0}$ & $\Delta \mathrm{H}^{0}$ & $\Delta \mathrm{S}^{0}$ & $\mathrm{E}_{\mathrm{s}}$ \\
\hline $\mathrm{SB}$ & 0.0 & -52.97 & 38.2 & 2.4 & 15.19 \\
& 0.1 & -52.161 & 36.0 & 0.4 & 14.65 \\
& 0.2 & -52.78 & 38.26 & -1.2 & 14.23 \\
$\mathrm{SBr}$ & 0.3 & -53.22 & -27.21 & -0.5 & 11.22 \\
& 0.0 & 83.16 & -229.2 & -4.3 & 14.18 \\
& 0.1 & 82.45 & -228.7 & -2.0 & 13.22 \\
$\mathrm{~N}$ & 0.2 & 82.66 & -227.9 & -3.3 & 13.16 \\
& 0.3 & 82.98 & -227.2 & 0.6 & 12.22 \\
& 0.0 & 112.21 & 106.4 & -5.2 & 10.02 \\
& 0.1 & 110.22 & 102.2 & -3.0 & 9.16 \\
& 0.2 & 110.36 & 104.6 & -2.5 & 9.08 \\
& 0.3 & 110.78 & -86.2 & 0.5 & 8.26 \\
\hline
\end{tabular}


The transfer thermodynamic quantities e.g. $\Delta \mathrm{G}_{\mathrm{t}}^{0}, \Delta \mathrm{H}_{\mathrm{t}}^{0}$ and $\Delta \mathrm{S}_{\mathrm{t}}^{0}$ for glycine in $0.1,0.2$ and $0.3 \mathrm{wt} \%$ of solutions of $\mathrm{SB}, \mathrm{SBr}$ and $\mathrm{N}$ at $25^{\circ} \mathrm{C}$ only are given in Table 3 . The effect of solvent on these quantities may be explained on the basis of the magnitude and sign of these quantities.

The free energy change for the transfer process, $\mathrm{MX}(\mathrm{W}) \rightarrow \mathrm{MX}(\mathrm{S})$ has been calculated in mole fraction scale and is given by

$$
\Delta \mathrm{G}_{\mathrm{t}}^{0}=\left({ }^{\mathrm{s}} \Delta \mathrm{G}^{0}{ }_{\mathrm{N}}-{ }^{\mathrm{w}} \Delta \mathrm{G}^{0}{ }_{\mathrm{N}}\right)
$$

Where the superscripts $\mathrm{W}$ and $\mathrm{S}$ refer to water and mixed solvents, respectively, and $\Delta \mathrm{G}^{0}$ values are given in mole fraction scale, as $\Delta \mathrm{G}^{0}{ }_{\mathrm{N}}=\Delta \mathrm{G}_{\mathrm{m}}^{0}-(\mathrm{v}-1) \times 2.303$ RT $\log (0.001 \overline{\mathrm{M}})$ where $v$ is the number of moles of ion produced from one mole of the solute and $\bar{M}$ is the average molar mass of concerned solution.

The entropy change $\left(\Delta \mathrm{S}_{\mathrm{t}}^{0}\right)$ and enthalpy change $\left(\Delta \mathrm{H}_{\mathrm{t}}^{0}\right)$ of transfer process have been derived by means of the following equations

$$
\begin{aligned}
\Delta \mathrm{S}_{\mathrm{t}}^{0} & =-\mathrm{d}\left(\Delta \mathrm{G}_{\mathrm{t}}^{0}\right) / \mathrm{dT} \\
\text { and } \Delta \mathrm{H}^{0}{ }_{\mathrm{t}} & =\Delta \mathrm{G}_{\mathrm{t}}^{0}+\mathrm{T} \Delta \mathrm{S}_{\mathrm{t}}^{0}
\end{aligned}
$$

The negative value of $\Delta \mathrm{G}_{\mathrm{t}}^{0}$ except in $\mathrm{N}$ solutions indicates that the overall effect of permittivity as well as of chemical nature. (which mainly reflects the relative basicity and solvating capacity) of the solvent makes the transfer of the solute (both cations and anions) from water to the mixed solvents favorable. In this case the ions (of the solute) appear to be in a lower free energy state in the mixed solvent than in water and hence the transfer is spontaneous.

The values of $\Delta \mathrm{H}_{\mathrm{t}}^{0}$ and $\Delta \mathrm{S}_{\mathrm{t}}^{0}$ suggest that when amino acid (glycine) is added to highly polar water molecule the mixed solvent becomes less associated than pure water. Thus, the transferred ion breaks more structure in pure water than in the mixed solvents. This is further supported by the fact that the transfer process is the structure forming process including the solvent of ions which is exothermic accompanied by entropy decrease.

\section{Conclusion}

The molar conductance values of glycine in aqueous solutions of $\mathrm{SB}, \mathrm{SBr}$ and $\mathrm{N}$ have been measured at temperatures ranging from $298.15 \mathrm{~K}$ to $313.15 \mathrm{~K}$. As observed, with increase of temperature, the conductance value goes on increasing. As the weight percentage of hydrotropic agent increases, less is the mobility of ions. This leads to low value of conductance. The ionassociation constant and thermodynamic parameters as well the as transfer thermodynamic quantities have been calculated and their role towards solvation has been discussed.

\section{Acknowledgement}

One of the authors (SP) is very much thankful to the President of the Governing Body, and the Principal, U.N. (Auto) College, Adashpur, Odisha for sanction of the leave for doing research work in I.T.E.R., S 'O' A University, Bhubaneswar.

\section{References}

1 Robinson R A and Stokes R H, Electrolyte Solutions, Butterworths, London, 1955, 35.

2 Pattnaik S and Dash U N, Asian J Res Chem., 2013, 6(1), 64.

3 Shedlovsky T and Kay R L, J Phys Chem., 1956, 60, 51.

4 Dash U N and Patnaik M R, Indian J Chem., 1996, 35A, 836.

5 Dash UN, Mohapatra J R and Lal B, J Mol Liq., 2006, 124, 13-18.

6 Glasstone S, An Indtroduction to Electrochemistry, Van Nostrand, New York, 1965.

7 Coetzee J F and Richi D, Solute-Solvent Interactions, Marcel Dekker, New York, 1976. 